\title{
Prediction of Pressure Drop and Ventilation in a Lit Cigarette
}

\author{
by \\ R.W. Dwyer and Peishi Chen \\ Philip Morris Research Center \\ P.O. Box 26583, Richmond VA 23261.
}

\section{SUMMARY}

In order to understand how the raw materials and processing contribute to the performance of the products, a mathematical model of pressure drop and ventilation in a lit cigarette has been developed. The model can be used to predict these parameters based on the geometry and properties of tobacco rod and filter, such as cigarette circumference, paper permeability, and design of filter vent rows. The model can be used to evaluate the contributions of variable components to the changes of pressure drop and ventilation of a lit cigarette.

\section{ZUSAMMENFASSUNG}

Um zu verstehen, wie Rohmaterial und Verarbeitung zu den Eigenschaften des Produkts beitragen, wurde ein mathematisches Modell zur Berechnung des Zugwiderstands und der Ventilation einer brennenden Cigarette entwickelt. Das Modell kann dazu dienen, diese Parameter, die sich aus der Geometrie und den Eigenschaften des Tabakstranges und des Filters, wie Durchmesser der Cigarette, Papierpermeabilität und Anordnung der Filterventilationslöcher, ableiten, vorherzusagen. Das Modell kann herangezogen werden, um den Beitrag variabler Größen auf Änderungen des Zugwiderstands und der Ventilation einer brennenden Cigarette $\mathrm{zu}$ bestimmen.

\section{RESUME}

Un modèle mathématique a été mis au point pour calculer la résistance au tirage et la ventilation d'une cigarette en cours de combustion, afin de comprendre dans quelle mesure la matière première et la préparation de tabac contribuent à la performance du produit. Le modèle peut servir a prédire ces paramètres qui dépendent de la géométrie et les propriétés du boudin de tabac, tels que le diamètre de la cigarette, la perméabilité du papier et la forme des trous de ventilation. Ce modèle peut servir à évaluer la contribution de divers facteurs aux changements de la résistance au tirage et de la ventilation d'une cigarette en cours de combustion.

\section{INTRODUCTION}

Two important factors that affect the performance of cigarette products are pressure drop and ventilation level. It is well known that the resistance to draw of a cigarette increases about 50 to $60 \%$ when it is lit (1-2) and the increased pressure drop of a lit cigarette is associated with the high temperature of the burning coal. The use of ventilated filters and higher permeability wrapper reduce the component level in smoke. Therefore, the geometry and properties of tobacco rod and filter have an impact on the overall flow resistance as well as the performance of a lit cigarette. 
Several investigators have developed models to predict the effects of various parameters on the resultant ventilation for lit cigarettes $(2,8-11)$, but little effort has been made to study the effect of the burning coal at different puff positions. The intention of this study is to develop a mathematical model based on the current knowledge to evaluate the contributions of variable components, including the burning coal, to the changes of pressure drop and ventilation of a lit cigarette.

\section{THEORETICAL BACKGROUND}

Figure 1 illustrates a lit cigarette with a ventilated filter. The lit cigarette has a butt length of $L_{B}$ and a circumference $C_{r}$. The lit cigarette is composed of a burning coal, an unburned tobacco rod covered with an air-permeable wrapper, and a filter covered with air-impermeable tipping paper perforated with ventilation rows. A small section of tobacco column adjacent to the filter is also covered by the tipping paper. Some products have more than one row of vents. Each ventilation row is characterized by a position $x_{i}$ and a weighting $w_{i}$, which is related to the relative open area of the row.

Under simulated puff conditions, the air flow at the outlet end of the filter section, $Q_{o u}$, is controlled at a standard flow rate $Q_{0}\left(17.5 \mathrm{~cm}^{3} / \mathrm{s}\right)$. The total pressure drop of the unlit cigarette, $\Delta P$, and the filter pressure drop without ventilation, $\Delta P_{F}^{0}$, are often measured at a standard flow rate $Q_{0}$. The filter ventilation under the unlit condition, $D$, is also measured.

The flow of air into each vent row, $Q_{v i}$, depends on the pressure drop across the holes in that row. The pressure drop across the row, $\Delta P_{v i}$, is equal to the total pressure drop across the upstream portion of the lit cigarette. Therefore, the air flow of the vent row depends on the flow rate and pressure drops of each segments in the upstream portion of the lit cigarette.

For a lit cigarette, the flow of air through the wrapper varies with the butt length and the pressure drop of the burning coal. The flow of air through the wrapper of a given element $d x^{\prime}$ can be described by the following equation, where $x^{\prime}$ is the distance of the element from the char line, and $Q_{p}\left(x^{\prime}\right)$ is the accumulative flow of air through the wrapper section from 0 to $x^{\prime}$,

$$
\frac{d Q_{P}\left(\dot{x}^{\prime}\right)}{d \dot{x}^{\prime}}=k \alpha C_{r}\left[\Delta P_{r}\left(x^{\prime}\right)+\Delta P_{c}\right]
$$

where $k$ is constant and $a$ is the wrapper porosity. With the unit of length in $\mathrm{cm}$, flow in $\mathrm{cc} / \mathrm{s}$, viscosity in CORESTA, and pressure drop in $\mathrm{cm} \mathrm{H}_{2} \mathrm{O}, k=1 / 600$ (3). For a given length of a tobacco column $L_{r}$, the pressure drop of the burning coal $\Delta P_{c}$ is independent of $\mathrm{x}^{\prime}$. Considering the relationship between the pressure drop of the tobacco rod, $\Delta P_{r}$, and the flow through a tobacco column wrapped in an air-impermeable paper, $Q(3,4)$, equation [1] becomes

$$
\begin{aligned}
& \frac{d\left[\Delta P_{r}+\Delta P_{c}\right]}{d x^{\prime}} \\
& =\frac{\Delta P_{r e}^{0}\left(L_{r}\right)}{I_{r}}\left[a Q\left(\dot{x}^{\prime}\right)+b Q\left(\dot{x}^{\prime}\right)\right]
\end{aligned}
$$

where $a$ and $b$ are constants for a wide range of tobacco fillers, $a=0.042$, and $b=0.00086$ (3). $\Delta P_{r e}{ }^{0}$ is the pressure drop of the above tobacco column at the standard air flow. Combining the above two equations, it follows that,

$$
\begin{aligned}
& \frac{d^{2} Q_{p}\left(\dot{x}^{\prime}\right)}{d \dot{x}^{2}} \\
& =\frac{k \alpha C_{r} \Delta P_{r e}^{0}}{L_{r}}\left[a Q\left(\dot{x}^{\prime}\right)+b Q\left(\dot{x}^{\prime}\right)^{2}\right]
\end{aligned}
$$

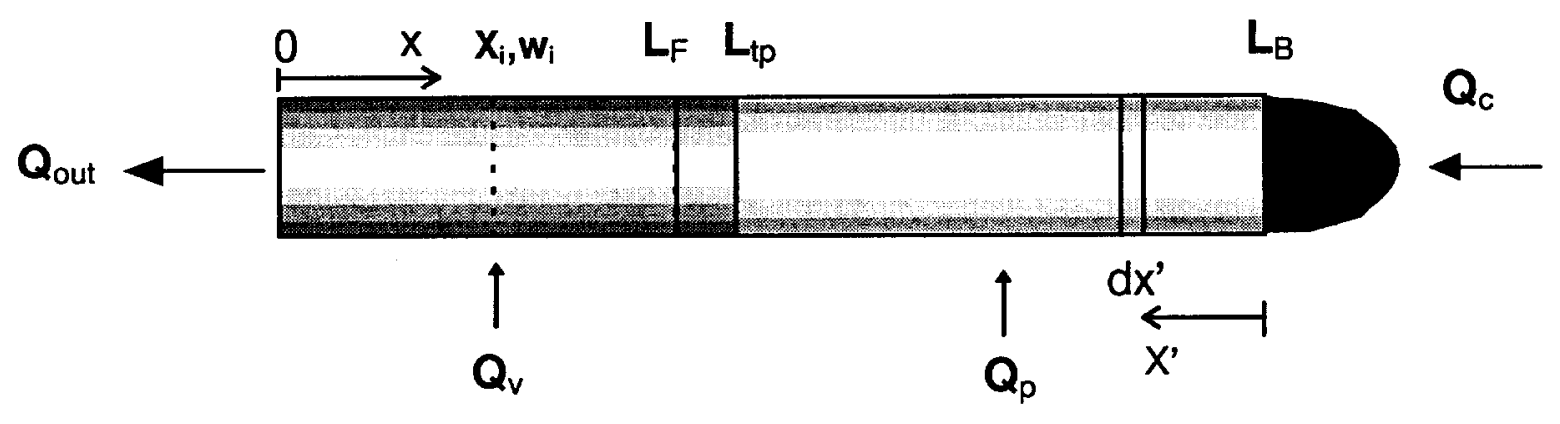

Figure 1.

A lit cigarette with a ventilated filter. 
By defining $\overline{Q_{p}}\left(\dot{x}^{\prime}\right)=Q_{p}\left(\dot{x}^{\prime}\right)-Q_{p}\left(L_{r}\right)$ or

$$
\mathscr{Q}(\dot{x})=\overline{Q_{p}}\left(\dot{x}^{\prime}\right)+\mathscr{Q}\left(L_{r}\right)
$$

and substituting the defined variables into equation [3], it becomes

$$
\begin{aligned}
\frac{d^{2} \overline{Q_{p}}\left(\dot{x}^{\prime}\right)}{d \dot{x}^{\prime 2}}= & \frac{k \alpha C_{r} \Delta P_{r e}^{0}}{L_{r}} \\
& \left\{a\left[Q\left(L_{r}\right)+\overline{Q_{p}}\left(\dot{x}^{\prime}\right)\right]+b\left[Q\left(L_{r}\right)+\overline{Q_{p}}\left(\dot{x}^{\prime}\right)\right]^{2}\right\}
\end{aligned}
$$

Neglecting the second order term on the right hand side, results in

$$
\begin{aligned}
& \frac{d^{2} \overline{Q_{p}}\left(\dot{x}^{\prime}\right)}{d \dot{x}^{2}}-\frac{k \alpha C_{r} \Delta P_{r e}^{0}}{L_{r}}\left[a+2 b Q\left(L_{r}\right)\right] \overline{Q_{p}}\left(\dot{x}^{\prime}\right) \\
& =\frac{k \alpha C_{r} \Delta P_{r e}^{0}}{L_{r}}\left\{a Q\left(L_{r}\right)+b Q\left(L_{r}\right)^{2}\right\}
\end{aligned}
$$

Solving the above equation gives

$$
\begin{aligned}
\overline{Q_{p}}\left(\dot{x}^{\prime}\right) & =A \cosh \left(m \dot{x}^{\prime}\right)+B \sinh \left(m \dot{x}^{\prime}\right) \\
& -\frac{a Q\left(L_{r}\right)+b Q\left(L_{L_{r}}\right)^{2}}{a+2 b Q\left(L_{r_{r}}\right)}
\end{aligned}
$$

where $\quad m^{2}=\frac{k \alpha C_{r} \Delta P_{r e}^{0}}{L_{r}}\left[a+2 b Q\left(L_{r}\right)\right]$

Application of the following boundary conditions (B.C.) provides solutions for $A$ and $B$ :

B.C. $1: \overline{Q_{p}}(0)=-Q_{p}\left(L_{r}\right)$

$$
\begin{aligned}
A & =\frac{a Q\left(L_{r}\right)+b Q\left(L_{r}\right)^{2}}{a+2 b Q\left(L_{r}\right)}-Q_{p}\left(I_{r}\right) \\
& =G-Q_{p}\left(L_{r}\right)
\end{aligned}
$$

where

$$
G=\frac{a Q\left(L_{r}\right)+b Q\left(L_{r}\right)^{2}}{a+2 b Q\left(L_{r}\right)}
$$

B.C. 2: $\left.\frac{d \overline{Q_{p}}\left(\dot{x}^{\prime}\right)}{d \dot{x}^{\prime}}\right|_{x^{\prime}=0}=k \alpha C_{r} \Delta P_{c}$

$$
B=\frac{k \alpha C_{r} \Delta P_{c}}{m}
$$

The coal alters the flow pattern inside the cigarette, changing the level of ventilation compared to an unlit cigarette. Usually, the ventilation level rises in the first two puffs due to the non-stabilized coal. As the tobacco rod becomes shorter during smoking, less air is drawn through the wrapper and the filter ventilation decreases. The pressure drop across the burning coal is assumed to obey Darcy's law and the air flow through the coal, $Q_{0}$, is assumed to vary with the average gas temperature at the coal, $T_{c}$

$$
\Delta P_{c}=\frac{\mu_{T_{c}}}{\beta} Q_{c}\left(T_{c}\right) L_{t}
$$

where $\mu_{T c}$ is the gas viscosity and $\beta$ is constant. The coal length $L_{c}$ is assumed constant for all the puffs but the first one due to the non-stabilized coal. Since the overall pressure inside the coal is near atmospheric, the relationship of flow and temperature is assumed to obey the ideal gas law and the gas viscosity is a function of temperature in the gas temperature range of interest,

$$
\mathscr{L}_{c}\left(T_{c}\right)=\mathscr{Q}_{c}\left(T_{0}\right) \frac{T_{c}}{T_{0}}, \quad \mu_{T_{0}}\left(\frac{T_{c}}{T_{0}}\right)^{0.73}
$$

At room temperature $T_{0}$, the pressure drop of the coal at the standard air flow is determined by,

$$
\Delta P_{c}^{0}=\frac{\mu_{T_{0}}}{\beta} Q_{0} L_{c}
$$

Substituting the above equations into equation [11] and using $Q_{c}\left(T_{0}\right)=Q\left(L_{r}\right)-Q_{p}\left(L_{r}\right)$, it follows that

$$
\begin{aligned}
\Delta P_{c} & =\frac{\Delta P_{c}^{0}}{Q_{0}} \frac{\mu_{T_{c}}}{\mu_{T_{0}}}\left(\frac{T_{c}}{T_{o}}\right) Q_{c}\left(T_{0}\right) \\
& =\frac{\Delta P_{c}^{0}}{Q_{0}}\left(\frac{T_{c}}{T_{0}}\right)^{1.73}\left[Q\left(L_{r}\right)-Q_{p}\left(L_{r}\right)\right]
\end{aligned}
$$

The average gas temperature at the coal is associated with the combustion process occurring in the coal and the heat loss to the environment. The maximum solid-phase temperature has been measured by several investigators $(1,5,6)$. The experimental data show that the maximum solid temperature increases with the puff volume or the air flow through the coal. Based on the experimental results of the measured maximum coal temperatures at different puff volumes or air flows through the coal $(5,6)$, it is assumed that the average gas/solid temperature and the air flow through the coal has the following relationship, as shown in Figure 2,

$$
T_{c}=T_{c 0}+120 Q_{c}\left(T_{0}\right)^{0.33}
$$


$T_{\infty}$ is taken as the char line temperature, $\sim 450{ }^{\circ} \mathrm{C}$. Combining equations [14] and [15], and using the following approximate expression, it follows that

$$
\begin{aligned}
\Delta P_{c}= & \frac{\Delta P_{c}^{0}}{Q_{0}}\left\{d_{0}+d_{1}\left[Q\left(L_{r}\right)-Q_{p}\left(L_{r}\right)\right]^{n}\right\} \\
& {\left[Q\left(L_{r}\right)-Q_{p}\left(I_{r}\right)\right] }
\end{aligned}
$$

where the parameters, $d_{0}=4.688, d_{1}=1.409\left[\left(\mathrm{~cm}^{3} / \mathrm{s}\right)^{-1 / \mathrm{n}}\right]$, and $n=0.363$, are determined by regression in the coal temperature range $\left(450-800^{\circ} \mathrm{C}\right)$. Equation [10] can then be written as

$$
\begin{aligned}
B & =\frac{k \alpha C_{r} \Delta P_{c}}{m}=h Q_{c}\left(T_{0}\right) \\
& =h\left[Q\left(L_{+}\right)-Q_{p}\left(L_{t}\right)\right]
\end{aligned}
$$

B.C. 3: $\overline{Q_{p}}\left(L_{r}\right)=0$

$$
\begin{aligned}
& {\left[G-Q_{p}\left(L_{r}\right)\right] \cosh \left(m L_{r}\right)} \\
& +h\left[Q\left(L_{+}\right)-Q_{p}\left(L_{r}\right)\right] \sinh \left(m L_{r}\right)=G
\end{aligned}
$$

The total air flow through the wrapper can then be obtained,

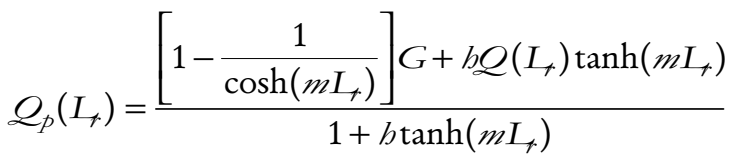

Since $b$ is a function of $Q_{c}$, iterations are required to solve for $Q_{p}\left(L_{r}\right)$. The pressure drop of the tobacco column plus the burning coal is

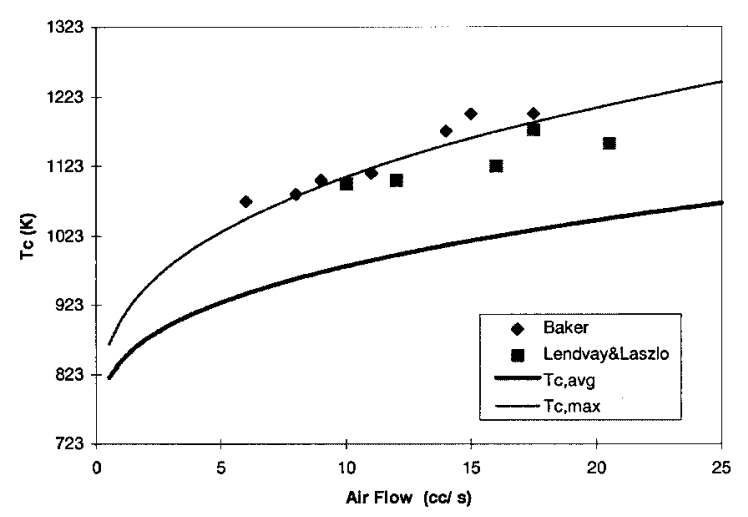

\begin{tabular}{|c|c|}
\hline Parameter & Property \\
\hline$L_{0}$ (Cigarette length) & $8.4 \mathrm{~cm}$ \\
\hline$L_{F}$ (Filter length) & $2.1 \mathrm{~cm}$ \\
\hline$L_{t p}$ (Tipping length) & $2.5 \mathrm{~cm}$ \\
\hline$C_{r}($ Circumference $)$ & $2.5 \mathrm{~cm}$ \\
\hline$W$ (Rod weight) & $0.799 \mathrm{~g}$ \\
\hline$\alpha$ (Wrapper permeability) & $\begin{array}{r}62.3,25.1 \\
\text { CORESTA }\end{array}$ \\
\hline $\begin{array}{l}\Delta P \text { (Cigarette pressure drop at } \\
\text { standard flow })\end{array}$ & $11.0 \mathrm{~cm} \mathrm{H}_{2} \mathrm{O}$ \\
\hline $\begin{array}{l}\Delta P_{F}^{0} \text { (Encapsulated filter pressure } \\
\text { drop at standard flow) }\end{array}$ & $6.0 \mathrm{~cm} \mathrm{H}_{2} \mathrm{O}$. \\
\hline$D$ (Filter dilution) & $0.172,0.6$ \\
\hline$x_{1}$ (Ventilation row position) & $1.2 \mathrm{~cm}$ \\
\hline $\begin{array}{l}w_{1}(\text { Ventilation row open-area } \\
\text { weighting })\end{array}$ & 1.0 \\
\hline
\end{tabular}

Figure 2.

Coal temperature vs. air flow through the coal; $T_{c}=$ gas temperature at the coal.
Table 1.

Test cigarette properties (HARVARD (7)).

$$
\begin{aligned}
& \Delta P_{r}\left(L_{r}\right)+\Delta P_{c} \\
= & \frac{m\left[G \tanh \left(m L_{r}\right)\right]}{k \alpha C_{r}} \\
+ & \frac{m b\left[Q\left(L_{r}\right)-Q_{p}\left(I_{r}\right)\right] \frac{1}{\cosh \left(m L_{r}\right)}}{k \alpha C_{r}}
\end{aligned}
$$

The calculation of the filter ventilation and the pressure drop and flow through the tipping paper uses the same approach as that of DWYER et al. (3) for unlit cigarettes. As the butt length becomes shorter, the flow through the coal increases, the upstream pressure drop and the filter ventilation vary, therefore iterations are required to calculate the filter ventilation and total pressure drop for a lit cigarette. The above calculation procedure has been validated through the experimental results of HARWARD (7). Table 1 lists the properties of the test cigarettes used by HARWARD.

The calculated results of filter ventilation and total pressure drops at different puff positions agree with the experimental data, as shown in Figures 3-6. Figures $3 \mathrm{a}$ and $3 \mathrm{~b}$ show the results of a cigarette with $17.2 \%$ ventilation and the porosity of the wrapper is 62.3 CORESTA. Figures $4 \mathrm{a}$ and $4 \mathrm{~b}$ show the results of a cigarette with $17.2 \%$ ventilation and a 25.1 CORESTA 


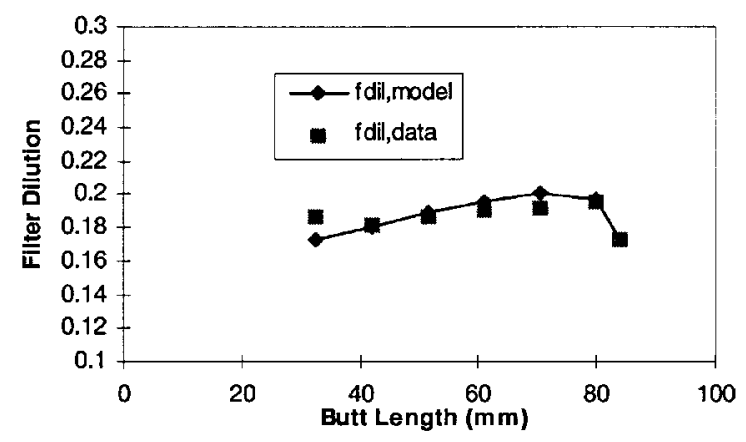

Figure 3a.

Filter dilution (fdil) vs. butt length (17.2\% ventilation, 62.3 CORESTA paper).

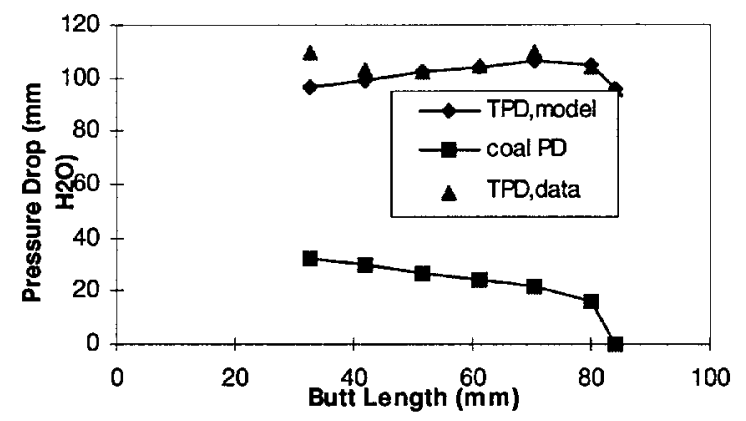

Figure 3b.

Total pressure drop (TPD) vs. butt length (17\% ventilation, 62.3 CORESTA paper).

wrapper. Figures $5 \mathrm{a}, \mathrm{b}$ and $6 \mathrm{a}, \mathrm{b}$ show the results of cigarettes with $60 \%$ ventilation. The coal pressure drop at room temperature and standard air flow $\Delta P^{0}$, used in the calculation is $0.5 \mathrm{~cm} \mathrm{H}_{2} \mathrm{O}$. The assumption of a lower coal pressure drop $\left(0.375 \mathrm{~cm} \mathrm{H}_{2} \mathrm{O}\right)$ for the first puffs worked for all the cases. Theoretically, as the puff number increases, the butt length decreases and the cigarette pressure drop decreases. However, the experimental results of the last puffs show that the pressure drop increases with the last few puffs, this may be due to the higher temperature of the unburned tobacco rod behind the char line (2) and longer coal length. The effects of ventilation on product performance are more

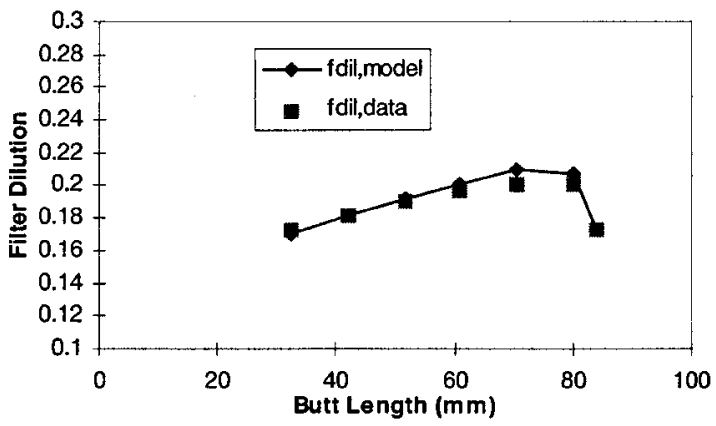

Figure 4a.

Filter dilution (fdil) vs. butt length (17\% ventilation, 25.1 CORESTA paper).

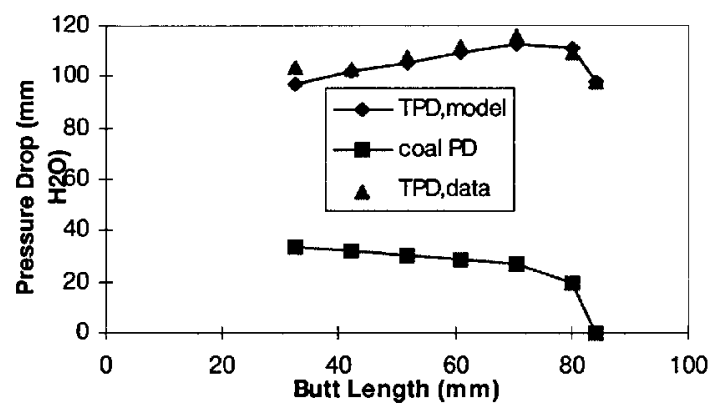

Figure 4b.

Total pressure drop (TPD) vs. butt length (17.2\% ventilation, 25.1 CORESTA paper).

than just dilution of the smoke. Increasing the ventilation causes a smaller proportion of the puff volume to be drawn in through the burning coal. Thus, the intensity of the combustion process inside the coal will be reduced and the coal temperature will be lower. The pressure drop of the burning coal is not constant but varies with the ventilation level and puff position. Figure 7 shows the calculated coal pressure drop versus the calculated total dilution when the butt length is $5.15 \mathrm{~cm}$. As shown in Figure 7, that the pressure drop of a burning coal without dilution can reach 4 to $5 \mathrm{~cm} \mathrm{H}_{2} \mathrm{O}$, which means an 8-9 fold increase, which indicates that the effect of air flow through the coal on burning coal temperatures as well as pressure drops is quite significant. 


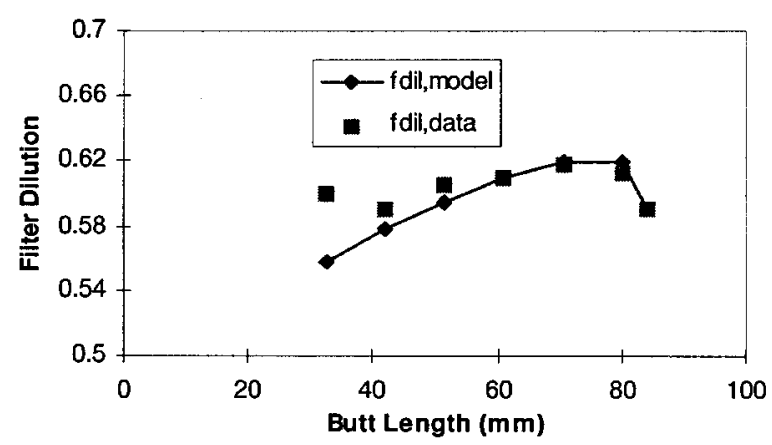

Figure 5a.

Filter dilution (fdil) vs. butt length $(59.1 \%$ ventilation, 62.3 CORESTA paper).

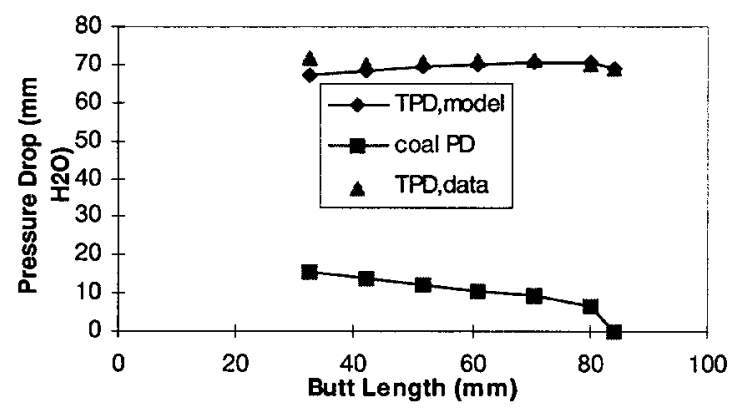

Figure 5b.

Total pressure drop (TPD) vs. butt length (59.1\% ventilation, 62.3 CORESTA paper).

\section{CONCLUSIONS}

A mathematical model of pressure drop and ventilation in a lit cigarette has been developed. With the geometry and properties of tobacco rod and filter, such as cigarette circumference, paper permeability, and design of filter vent rows as inputs, the model can be used to predict the pressure drop and ventilation of a lit cigarette and to evaluate the contributions of variable components including properties of the raw materials and processing accuracy to the changes of the yields.

The coal pressure drop at room temperature and standard air flow $\Delta P^{0}$ is relatively small, $\sim 0.5 \mathrm{~cm} \mathrm{H}_{2} \mathrm{O}(0.375 \mathrm{~cm}$ $\mathrm{H}_{2} \mathrm{O}$ for the first puff), however the pressure drop of a burning coal without dilution can reach 4 to $5 \mathrm{~cm} \mathrm{H}_{2} \mathrm{O}$, which means an 8-9 fold increase.

The effects of ventilation on product performance are more than just dilution of the smoke. Increasing the ventilation causes a smaller proportion of the puff volume to be drawn in through the burning coal. Thus, the intensity of the combustion process inside the coal

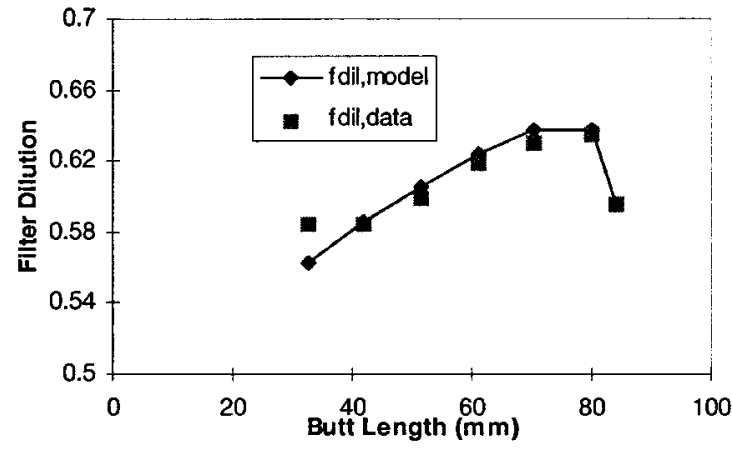

Figure 6a.

Filter dilution (fdil) vs. butt length $(59.6 \%$ ventilation, 25.1 CORESTA paper).

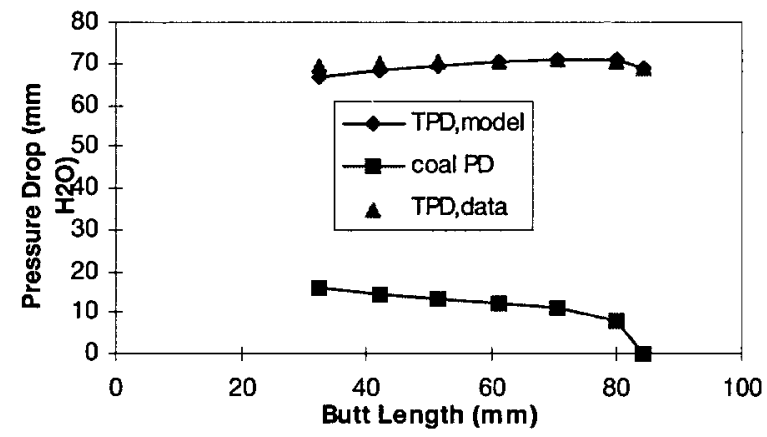

Figure 6b.

Total pressure drop (TPD) vs. butt length (59.6\% ventilation, 25.1 CORESTA paper).

will be reduced and the coal temperature will be lower. Therefore, the pressure drop of the burning coal is not constant but varies with the ventilation level and puff position.

\section{REFERENCES}

1. Baker, R.R.: The effect of ventilation on cigarette combustion mechanisms; Recent Adv. Tob. Sci. 10 (1984) 88-150.

2. Baker, R.R.: Contributions to the draw resistance of a burning cigarette; Beitr. Tabakforsch. 8 (1975) 124-131.

3. Dwyer, R.W., K.H. Cox, and J.E. Bickett: Source of pressure-drop and ventilation variability in cigarettes; Recent Adv. Tob. Sci. 13 (1989) 82-118.

4. Riley, D.S., D.G. Drake, R.R. Baker and D.P Robinson: Non-darcy flow and diffusion in a tobacco rod; PCH PhysicoChemical Hydrodynamics 7 (1986) 255-279. 


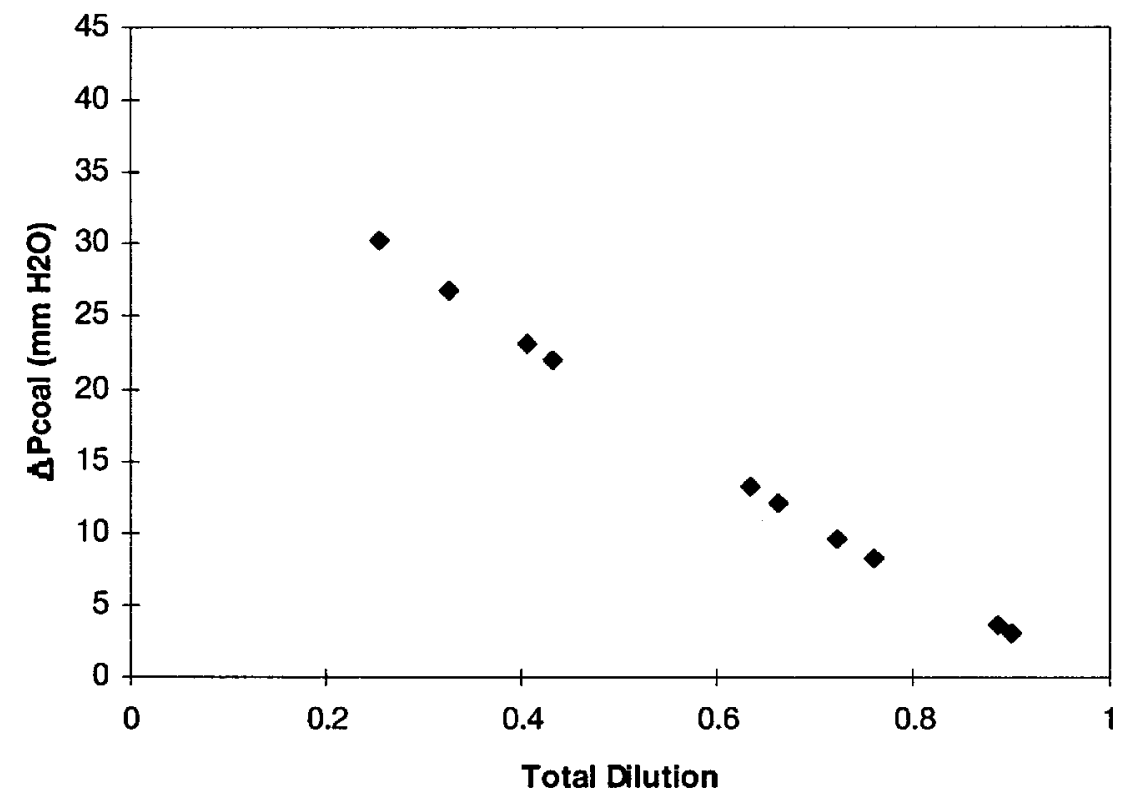

Figure 7.

Coal pressure drop vs total dilution (butt length $=51.5 \mathrm{~mm}$ )

5. Baker, R.R.: Development of temperature distribution inside the reaction zone of a burning cigarette; in: Thermal analysis, Proceedings of the $6^{\text {th }}$ International Conference on Thermal Analysis, edited by H.G. Wiedemann, Birkhauser Verlag, Basel, Boston, Stuttgart, 1980, pp V1:439-444.

6. Lendvay, A.T. and T.S. Laszlo: Cigarette peak coal temperature measurements; Beitr. Tabakforsch. 7 (1974) 276-281.

7. Harward, C.N.: personal communication, 1986.

8. Parker, J.A. and R.T Montgomery: Design criteria for ventilated filters; Beitr. Tabakforsch. Int. 10 (1979) 1-6.

9. Schneider, W., A. Schlüter and F. Seehofer: The effects of the properties of materials in a cigarette on filter ventilation; Beitr. Tabakforsch. Int. 12 (1984) 123-136.
10. Selke, W.A. and J.H. Mathews: The permeability of cigarette papers and cigarette ventilation; Beitr. Tabakforsch. 9 (1978) 193-200.

11. Meyer-Abich, K.M.: Die Strömungsverhältnisse in Cigaretten; Beitr. Tabakforsch. 3 (1966) 307-329.

Address for correspondence

Peishi Chen

Philip Morris

Research and Development

P.O. Box 26583

USA - Richmond, VA 23261 